\title{
Brazil's Commitment to Train the Next Generation of Water Leaders: the Potential Role of UNESCO-Hidroex
}

\author{
Octavio Elisio A. Brito ${ }^{1}$, Tania A. S. Brito ${ }^{1} \&$ Richard A. Meganck ${ }^{2}$ \\ ${ }^{1}$ UNESCO-Hidroex, Minas Gerais, Brazil \\ ${ }^{2}$ UNESCO-Hidroex, Silverton Oregon, USA \\ Correspondence: Richard A. Meganck, UNESCO-Hidroex, Silverton Oregon, USA. E-mail: \\ rameganck@gmail.com
}

Received: April 8, 2014 Accepted: May 7, 2014 Online Published: May 13, 2014

doi:10.5539/enrr.v4n3p1 URL: http://dx.doi.org/10.5539/enrr.v4n3p1

\begin{abstract}
Brazil has made a strategic decision and formal commitment to the International Community to invest in developing a post-graduate water education center to help train the next generation of water leaders in Latin America and Portuguese-speaking Africa in response to the demand of the UNESCO Member States. The International Centre for Education, Capacity Building and Applied Water Research - Hidroex will, overtime, greatly augment the work of the UNESCO Institute for Water Education (UNESCO-IHE) in Delft, the Netherlands as a member-institution of the proposed UNESCO Global Campus for Water Education. This center of excellence will also develop a new institutional model in two regards: first by implementing the concept of a "water condominium" which will attract scientists from around the world sharing a common research interest providing logistical support including laboratories, analytical capacity, video conference facilities and offices all with the aim of addressing complex, priority water research issues, and resulting in new networks of collaborating scientists, and secondly by integrating the goals of eighth phase of the UNESCO International Hydrological Program into the education and research programs of Hidroex to develop the environmental conscience of all citizens - from young children to the highest level of technical knowledge - within an appropriate cultural context. This paper documents the institutional roadmap, logic and progress in realizing that ambitious goal.
\end{abstract}

Keywords: water education, UNESCO centers, UNESCO global campus, UNESCO International Hydrological Program Centers

\section{Background}

In June 2007, the International Hydrological Program of the United Nations Educational, Scientific and Cultural Organization (UNESCO-IHP) endorsed the request from the Federal Republic of Brazil, through the State of Minas Gerais, to establish a UNESCO-sponsored Category II (UNESCO) (Note 1) center named the International Centre for Education, Capacity Building and Applied Water Research (Hidroex).The broad nature of the cooperation between UNESCO and Hidroex, as stated in the Brazilian proposal to the IHP, is to:

- Exchange water-related research within the UNESCO IHP and UNESCO Centers and Institutes.

- Promote and develop joint projects, courses, workshops and seminars related to improving the management of water resources.

- Jointly design and implement training tools, with special emphasis to Latin America and Portuguese-speaking African countries.

- Disseminate the results of technical knowledge generated through education and research efforts to the widest possible national and international audiences.

The 35th UNESCO General Conference approved the Category II center proposal in October 2009 in line with the criteria for such undertakings (Note 2). This was an essential step in the "internationalization" of the Hidroex Foundation and a legal requirement in Brazil for the center to be able to function both nationally and internationally as per UNESCO rules for Category II centers (Note 3). By late 2009 all of the legal documents formally establishing the Hidroex Foundation in Brazil were completed (Note 4) and in May of 2010 the legal 
Decree issued. As a result, Hidroex became a legal entity empowered to "enter into agreements with both national and international bodies and individuals and to make independent financial decisions benefiting its future development" (Note 5).

Immediately after the Decree was issued by the Legislature of the State of Minas Gerais, a Letter of Intent was signed to utilize the proven experience of the UNESCO-Institute for Water Education (UNESCO-IHE to assist in the complex process of planning and developing the education, research and capacity development framework and to implement specific pilot activities in the 2011-2014 period. This Letter of Intent was executed through two contracts with UNESCO-IHE - one that proposed a capacity strengthening program for the 2011-2014 period through post-graduate training for future Hidroex staff (Note 6), and a second detailed workplan that outlined the specific timetable, course content and administrative assistance to be provided by UNESCO-IHE to Hidroex in the 2012-2014 period (Note 7). Since that time, the development of the programmatic aspects of Hidroex as a Category II center has been undertaken together with UNESCO-IHE and other national and international partners. Planning the physical infrastructure of the Hidroex campus was the direct responsibility of the State of Minas Gerais through the office of the State Secretary for Science, Technology and Higher Education (SECTES) with financing provided by both the State and Federal Governments.

\section{Vision - Hidroex as a UNESCO Category I Institute}

As a Category 1 Institute, Hidroex envisions making a tangible contribution to resolving the burgeoning water crises facing Latin America and Portuguese-speaking Africa by helping to train the next generation of water leaders, promising a time when water resources are shared in an equitable fashion and managed in a sustainable context. In addition, Hidroex will employ a new institutional model, one that will integrate IHP-VIII goals into the education and research programs of Hidroex to develop the environmental conscience of all citizens - from young children to the highest level of technical knowledge - within an appropriate cultural context.

\section{The Need for a Second Category 1 Water Training Institute}

UNESCO-IHE is widely recognized as a premier post-graduate institute training the next generation of water leaders, the largest graduate school of its kind in the world and one of only two category I UNESCO Science Institutes. (Note 8) The demand for access to all of IHE's "products" continues to expand - MSc and PhD study/research programs, short and tailor-made courses, on-line courses, as well as consulting services. In spite of signing several agreements to attempt to expand its educational outreach through national and regional groupings such as with the Amsterdam Water Authority (WATERNET) through its programs in Africa, IHE is still overwhelmed, receiving nearly 2,500 applications annually while only being able to accept 1 in 10 qualified applicants to its MSc program (Note 9). IHE currently has more than $125 \mathrm{PhD}$ fellows and several post-doc researchers. It is quite literally bursting at the seams and yet the Member States continue to stress the importance of water education. IHP-VIII gives special emphasis to this need while the factors limiting IHE's ability to accept more students are seemingly intractable - physical space (classroom, lab and dormitory) as well as the number of available fellowships. However, the need for more delivery capacity is obvious to even the casual observer. In its 57-year history IHE enhanced the capacities of more than 16,500 water professionals from 162 countries, including awarding some 12,500 $\mathrm{MSc}$ and $150 \mathrm{PhD}$ degrees. But from an institutional and organizational standpoint, the situation has become untenable. Simply stated UNESCO-IHE needs assistance, beyond what the network of category II centers can provide.

Since early in 2004 Brazil indicated a desire to assist UNESCO in meeting this increasing demand. While it took several years to mesh the bureaucracies of the State, the Federal Government and UNESCO, it finally became a reality, as noted above in late 2009. 


\section{Hidroex Mission}

Hidroex realizes its vision through implementing world-class education, research and capacity development programs in the broad context of sustainable use of water resources in Latin America and Portuguese-speaking Africa in: (i) integrated water and river basin governance, (ii) management of water and sanitation services and the application of new technologies, and (iii) cutting-edge agricultural irrigation strategies and methods.

\section{Is Brazil Prepared to Be An Integral Component of the Global Water Campus?}

Brazil has the experience in the water sector, the institutional support at both the State and Federal levels, the commitment internationally to impact water resources management, and the financial capability to undertake a project of this scale.

As will come as no surprise to even the casual observer of the evolution of international organizations and influence therein, Brazil has made a concerted effort to increase its international profile through a number of mechanisms in recent years. Chief among those undertakings include its leadership role in the Southern Common Market regional trading group (MERCOSUR); its increasing influence in the BRICS alignment of Brazil, Russia, India, China and South Africa; its autonomy in international fora as an energy-independent nation, and its active role in both the International Monetary Fund and the World Bank, among other developments.

Brazil's is also internationally recognized as having invested in the development of a world-class system of State and Federal research and academic training institutions. This evolution as well as the growth of the National Water Agency (ANA) and its leadership role in the World Water Council (WWC) provides a stable platform from which to take the lead in water education, joining UNESCO-IHE as a partner in developing what has been conceived of as a coordinated approach to water education through the development of a Global Water Campus. And although it will take several years, to fully implement, Hidroex may be the first campus to join forces with UNESCO-IHE in this ambitious scheme.

The Global Campus concept (Figure 1) is one that may eventually include IHE-like facilities and IHE-affiliated institutions in several regions of the world. Brazil is the first Country to begin to institutionalize such an ambitious commitment by investing in Hidroex and the City of Water. In order for any such program to be effective however, it will have to involve many regional educational and research centers as well as those centers and chairs associated with the IHP. So, for example, Hidroex would have agreements with category 2 centers and IHP chairs in both Latin America and other regions as well as very close working relations with UNESCO-IHE. Overtime and with a fully functioning network of Campus members, a council of Rectors would logically emerge in response to the demands of the Members States to address specific education and research themes.

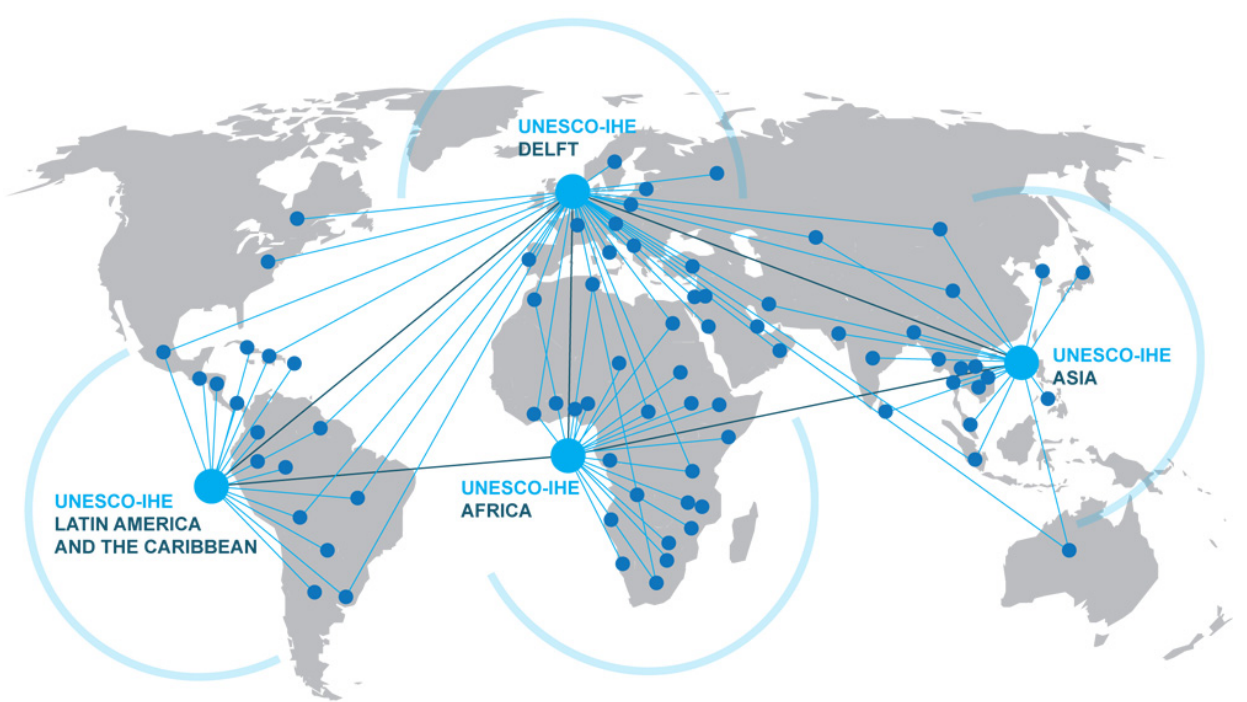

Figure 1. The global campus concept

Source: UNESCO-IHE (Hidroex could potentially fill the role of a category 1 center in Latin America). 


\section{Documenting the Institutional Growth of Hidroex}

It must be clearly stated that Hidroex fully understands the implications of a change in its status to that of a Category I center, and is prepared to address any implied risks that such a transfer might imply. Hidroex has made a concerted effort to develop its physical infrastructure, governance and administrative capabilities, its education and research staff and academic programs, all in the context of national and international partnerships required to address research problems on a global scale, as well as guarantee its long-term financial viability and academic integrity.

Hidroex is located in an education and research complex, referred to as the "City of Waters". This facility has an installed infrastructure of approximately $400,000 \mathrm{~m}^{2}$ and is composed of the Hidroex campus, the Water Condominium, private offices, institutional offices, a satellite campus of the State University of Minas Gerais (UEMG), all of which is available to Hidroex.

The scope, frequency and academic level of the educational offerings of Hidroex has steadily increased since 2010. Initially an effort was made to raise awareness in the host City - Frutal as to the importance of the development of Hidroex and via these programs gain the support of all sectors of society. This involved an early investment in developing the Yara Lins Ecocidadania (Eco-citizenship) Center in the City of Frutal. By offering courses for all educational levels and featuring the arts and cultural disciplines, the citizens of Frutal learned art skills but also gained an appreciation about Hidroex and its goals in sustainable management of the environment. Apart from this ongoing community education program, Hidroex has also and expanded its academic offerings, principally in partnership with UNESCO-IHE but involving other academic institutions from Brazil. This combination of community and cultural education with more formal and technical education represents a new model for category I centers within the UNESCO context. Examples of this dual approach include: (i) an arts-based environmental fair for children from both Frutal and Cape Verde, (ii) a joint MSc program with the Federal University of Ouro Preto (UFOP) that will be inaugurated in mid-2014, as well as technical courses offered with UNESCO-IHE in Cape Verde and Mozambique.

Physical Infrastructure and the City of Waters - Developing a campus to serve the needs of an estimated 1,200 students and staff necessitated substantial financial contributions from both the Federal Government and the State of Minas Gerais. To date, in the first phase, U.S. $\$ 42$ million was invested to plan and construct administrative offices, conference auditoria, eight wet-laboratories (Note 10), classrooms, a library and distance learning complex, 576 student dormitories, a cafeteria, a sports complex, as well as a satellite campus for the State University of Minas Gerais. The next phase, which will represent an additional investment of U.S.\$33 million, will include visiting faculty housing, roads and parking facilities and the Water Condominium. Without question, the Hidroex campus will be a world-class physical facility. The future administration of these facilities is planned to pass to UNESCO, but the infrastructure will logically remain the property of the State Government.

In this ambitious plan, development of a 'Water Condominium' must be given special note. One of the main objectives of IHP-VIII is to put science into action, by promoting the process of transformation of information and experience into answering local and regional needs for tools to adapt IWRM (Integrated Water Resources Management) to global changes and building competences to meet today's global water challenges. To this end, it is essential to establish knowledge platforms where stakeholders, researchers, local institutions, policy makers, and education entities can exchange and share the information, communicate each other, and develop new ideas in support of policy making and decision processes (Brito, Meganck, \& Romes, 2013). 


\section{The Water Condominium}

The Water Condominium is a unique concept that attracts scientists from around the world interested in addressing complex, priority research problems requiring inputs from social sciences, natural sciences and engineering disciplines. Currently the Water Condominium is composed of 18 institutions undertaking research and education in the priority water sector issues such including, among others, the Federal University of Minas Gerais (UFMG), Federal University of Ouro Preto (UFOP), Federal University of Viçosa (UFV), Federal University of Uberlandia (UFU), Federal University of the Triangle Region (UFTM), Federal University of Alfenas (UNIFAL), Federal University of Lavras (UFLA), Federal University of Itajuba (UNIFEI), Federal University of Juiz de Fora (UFJF), the State University of Minas Gerais (UEMG), Catholic Pontific University (PUC), Montes Claros University (UNIMONTES), Espirito Santo Federal University (UFES), Higher Technical Institute of Portugal (ISTP), National Water Institute of Argentina, (INA) UNESCO-IHE, National Water Agency of Brazil (ANA), and the Brazilian Agricultural Research Corporation (EMBRAPA). This facility will provide general infrastructure to visiting scientists sharing a research interest in a common theme of importance to the research efforts of Hidroex. The idea is to offer a synergistic environment in which groups of scientists can work together, exchange ideas and field-test such concepts. Scientists will be resident in Brazil for indeterminate periods and share the results of their research on common themes with colleague-scientists from around the world. Its outputs will aim to expand a holistic approach to water governance and management by balancing competing demands from diverse interests such as agriculture, industry, environment and domestic stakeholders with the context of climate change, population growth, and other realities confronting human progress. The goal is to help Member States adapt new strategies that will make both their ecosystems and socio-economic systems more resilient to such changes and offer decision-makers clear indications of the implications of decisions they are confronting.



Figure 2 . The campus is now nearly $60 \%$ completed

Governance and Administrative Capabilities - The President of Hidroex was named by the Governor of the State of Minas Gerais in mid-2010, and since that time approximately 35 administrative and support staff members have been added to Hidroex, including a Vice President, Chief of Staff, Senior Financial Officer, Legal Counsel, a Director of Research and a Director of Education. Some of the administrative staff are based in the State Capital of Belo Horizonte, while the majority are situated at its headquarters on the campus in the City of Frutal. The President maintains offices in both venues. The Governing Board (GB) of Hidroex was approved in accordance with IHP policies at their 2011 Intergovernmental Council and since that time has met twice - in 2012 and 2013. The center is proactive in terms of keeping the IHP Secretariat informed - both directly and through the three IHP-elected members of its GB. The membership of the Advisory Scientific Council was named by the Governor of Minas Gerais in early 2014 and includes both national and international members, 
representing high-level knowledge in water. The first meeting of that body was held in May 2014. While the administrative responsibility for Hidroex will pass to UNESCO requiring adjustments to its present organization, Brazil has demonstrated its ability to act within the existing policies governing category 2 centers and will adjust to the new administrative context upon designation as a category 1 center.

Education and Research Staff - The center has an academic staff including PhD and MSc levels. The existing contingent of academic staff is augmented by visiting staff from IHE and Brazilian institutions to present short courses, plan for the future curriculum of the center, and undertake research projects. This situation is recognized as a short-term solution for the start-up phase of Hidroex. It is understood that many additional and senior academic staff will have to be hired in the mid-term in order to coalesce research teams around priority themes and develop a respected teaching and research faculty. This is the highest priority in terms of building the staff of the institute. Several post-graduate students have also been contracted through project funding mechanisms to initiate a modest research effort, and a number of agreements have been signed with both national and international agencies and institutions to help establish the academic brand of Hidroex.

\section{Hidroex Vision for Education}

Hidroex will be an established and accredited post-graduate education destination for highly qualified and motivated students from Brazil, Latin America and Portuguese-speaking Africa, offering an MSc degree in priority disciplines, as well as a suite of short and tailor-made professional development courses.

Currently, there are 16 Brazilians studying at UNESCO-IHE; 5 at the MSc level, 4 at the PhD level and 5 undertaking post-doc research. Apart from that, there are $2 \mathrm{PhD}$ students studying at Oregon State University in the United States. Most of these students are supported through an agreement with the National Scientific and Technological Development Council $(\mathrm{CNPq})$ through the Science Without Borders program or through the Minas Gerais Research Support Foundation (FAPEMIG). These students are singled-out from the very large numbers of Brazilians studying water resources nationally and abroad, with support from various sources, because they have some affiliation with, and/or mid-term commitment to Hidroex once their studies are completed. When they have completed their studies, they will logically help Hidroex expand its faculty in the near-term. Some, depending on the source of their fellowship funding have a formal commitment to return to Hidroex for a specified period of time. Others, while having no formal commitment have expressed an interest in staff positions at Hidroex. The first group of these students obtained their MSc degrees in April of 2014 from UNESCO-IHE. 


\section{Hidroex Vision for Research}

Hidroex will have a robust research program in place headed by senior faculty, who together with students will generate new and developmentally-relevant applied research and thinking that addresses priority issues in the water sector; the results of which will impact water policies and management globally.



Figure 3. One of the new teaching labs at Hidroex

It is well recognized that while the core teaching and research staff may be built from the cadre of Brazilian students currently studying at UNESCO-IHE and other institutions, overtime, and with an open and UNESCO-controlled international recruitment process in place, foreign staff will be actively recruited. This need, while primarily based on the desire to build a faculty with distinct academic philosophies, is also a necessity in the UNESCO context. As the reputation of Hidroex as an academic institution matures, attracting senior staff will not be as much of an issue particularly applying the UNESCO recruitment process.

Academic Programs - At this point in time the experience of Hidroex to develop and offer formal education is being undertaken with UNESCO-IHE or with other academic institutions such as the Federal University of Ouro Preto (UFOP) and the Federal University of Lavras (UFLA), but installed institutional capacity is increasing at a rapid pace. Each year an increasing number of short courses are being offered and the amount of research being undertaken is also growing incrementally.

Initially an effort was made to raise awareness in the host City - Frutal as to the importance of the development of Hidroex and via these programs gain the support of all sectors of society. This involved an early investment in developing the Yara Lins Ecocidadania (Eco-citizenship) Center in the City of Frutal. By offering courses for all educational levels and featuring the arts and cultural disciplines, the citizens of Frutal learned art skills but also gained an appreciation about Hidroex and its goals in sustainable management of the environment. Apart from this ongoing community education program, Hidroex has also and expanded its academic offerings, principally in partnership with UNESCO-IHE but involving other academic institutions from Brazil. This combination of community and cultural education with more formal and technical education represents a new model for category I centers within the UNESCO context. Examples of this dual approach include: (i) an arts-based environmental fair for children from both Frutal and Cape Verde, (ii) a joint MSc program with the Federal University of Ouro Preto (UFOP) that was inaugurated in mid-2014, as well as technical courses offered with UNESCO-IHE in Cape Verde and Mozambique.

Since 2011, sixty-nine (69) short courses were offered nationally and nine (9) courses offered internationally in: Mozambique, Cape Verde, Argentina, Costa Rica, Uruguay, and Colombia, benefiting a total of 4,768 
professionals. These courses addressed the following themes: water quality management, integrated watershed management, risk management, and extreme climatic events. Additionally Hidroex staff participated in specialized training in Cape Verde, Costa Rica, Mexico, and Holland. It is anticipated that Hidroex will extend its relationship with UNESCO-IHE for at least another four years to ensure that it can meet its long-term academic responsibilities. The first group of MSc students to participate in a joint program between Hidroex and UFOP initiated their studies in mid-2014.

Since 2011, scientific research has been developed by Hidroex in partnership with several other research institutions on the following themes: integrated river basin management; recovery and conservation of soils and water resources; forest inventory; forest recovery in Permanent Preservation Areas; agro-ecological zoning; characterization of river habitats and inventory of aquatic biodiversity; environmental compliance; sustainable urban water management; water-related illness; payment for environmental services; history and culture of water; water education; invasive species; fisheries management; and wetlands management.

Institutional Partnerships - The principle institutional development partners of Hidroex include UNESCO-IHE and the members of the Water Condominium. To that end Hidroex entered into an agreement with IHE to provide assistance in operationalizing its academic and research programs. IHE has therefore been a near-constant partner in the development of Hidroex to this point in time; a relationship that will likely continue for the foreseeable future.

\section{Hidroex Vision for Partnerships}

HIDROEX embraces the value of creating institutional synergies through the development of pro-active partnerships in education, research and capacity development and views the development of such strategic partnerships as fundamental to its future as a post-graduate center in the water sector.

Brazil has always thought of Hidroex serving the training needs of neighboring countries in Latin America. This concept was expanded in mid-2010 to include developing an active partnership with the Community of Portuguese-Speaking Countries (CPLP) (Note 11). An Agreement was signed between Hidroex and the CPLP Secretariat in 2011. This is the cornerstone agreement that will allow Hidroex to fulfill its commitment to internationalize the center and deliver tangible products to other countries. To that end, the first short courses were offered in Cape Verde and Mozambique in 2013; the latter of which represents the first time that funding outside of the IHE contract was awarded in support of Hidroex activities (Note 12). This is a positive and very important milestone. Additionally, Hidroex has developed several key partnerships with a wide range of national and international education and research institutions and agencies, nearly 25 in total. They include UNESCO Category II centers, international NGOs such as the Cousteau Foundation and the International Center for Eco-hydrology (ICCE), several Federal and State universities, and key Federal agencies such as the National Water Agency (ANA) and the National Scientific and Technological Development Council (CNPq). 


\section{Hidroex Vision for Capacity/Institutional Development}

Hidroex will have established itself as an international water education and research center, with a solid basis for developing and eventually offering education services, undertaking research and building institutional partnerships in Brazil, Latin America and Portuguese-speaking Africa and be a sought after partner in providing demand-driven services in these areas.

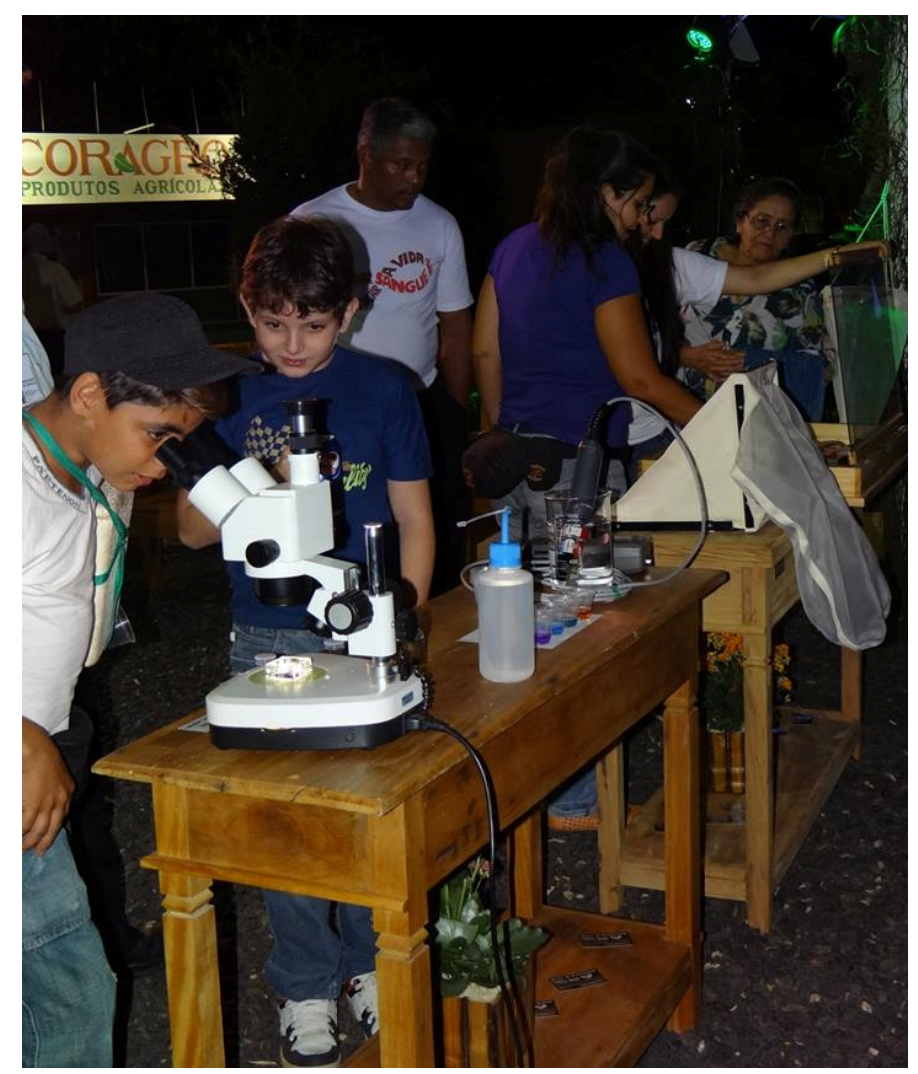

Figure 4. Students from the City of Frutal experience hands-on science

\section{Minimizing Any Potential Risk to Unesco}

The 193 Member states of UNESCO have, in general terms welcomed this initiative by Brazil to contribute to what one day might comprise a global campus for post graduate water education. However, they have at the same time made it quite clear that they are not prepared to assume any additional risk, either as individual Members States or as an international organization. The issues identified below were noted when UNESCO-IHE joined UNESCO and will certainly have to be clearly addressed if Hidroex is to gain the support of the Member States for transitioning to category I status.

Ensuring the Financial and Institutional Viability of Hidroex - The State Government has expressed a willingness to guarantee the financial viability and stability of Hidroex as per the requirements of UNESCO. As per other agreements of a similar nature, for example with the In International Center for Theoretical Physics (ICTP), the Director General of UNESCO, in accordance with the relevant provisions of the Organization's Financial Regulations, will establish a special account for the administration of these funds. The details of such a financial arrangement will be elaborated in the feasibility study to be undertaken by the IHP Secretariat and submitted to the UNESCO Executive Board for discussion at it meeting in the first quarter of 2015. The physical facilities of Hidroex will likely remain property of the State, while the administrative responsibility will pass to UNESCO.

Incorporating Existing Category II Staff into Hidroex Category I - Even though UNESCO will employ its recruitment procedures for hiring both local and international staff once Hidorex gains Category I 
status.However, consideration should be given to transitioning the existing staff to UNESCO employment, once they have successfully completed the UNESCO recruitment process. This issue will be negotiated between UNESCO and the Government of Brazil and a recommendation included in the report presented to Executive Board and the General Conference. The most likely scenario is that existing staff will be given preference in re-applying for existing positions reclassified under UNESCO policies.

Fellowship Support - Without question a large majority of the students who will eventually pursue post-graduate studies at Hidroex will require financial support. Hidroex will work within the existing national fellowship structure to ensure that all necessary financial support is provided to qualified students who gain acceptance to Hidroex (Note 13). This will eliminate any financial risk on the part of UNESCO to support students accepted to the study program.

Functional Autonomy - A Requirement for Academic Institutions - Hidroex has an academic focus and will address the issue of functional autonomy and academic freedom during the feasibility study phase. Hidroex already has a functioning GB and Scientific Advisory Council andthese bodies will be involved in developing policies relating to these issue.

\section{Summary}

The most daunting and immediate challenges Hidroex faces is to build credible academic education and research faculty and corresponding programs. This will obviously require several years before this Institute can safely assume its place among recognized and accredited centers of excellence in water on a global plane.

Notwithstanding this reality, Brazil has garnered the attention of the global community by proposing a radical approach to enhancing the educational capacity in the water resources sector. While this goal is in response to the demand of the UN Member States, Brazil has much to contribute to the complexity of managing water resources. This initiative will alter the course of how water professionals, particularly those from developing countries are trained for their future responsibilities. It will also further contribute to the global effort to not only train professionals, but to involve the local community in this process and help build solid networks of citizens concerned with water resources.

\section{References}

Brito, T., Meganck, R., \& Romes, L. (2013). Hidroex International Centre - An example of water cooperation. Free Flow - Reaching Water Security through Cooperation (p. 335). Paris: UNESCO Publishing.

\section{Notes}

Note 1. A UNESCO category I center is a National center whose mission and objectives are generally organized under the broad goals of UNESCO. A category I center is an integral component on UNESCO and responds directly to the mandates of the Member States.

Note 2. UNESCO General Conference, $35^{\text {th }}$ session. 2009. Implementation of the guidelines and criteria for category 2 institutes and centers approved in 33C/90.

Note 3. UNESCO General Conference, $33^{\text {rd }}$ session. 2005. Principles and guidelines regarding the establishment and operation of UNESCO institutes and centers (category I) and institutes and centers under the auspices of UNESCO (category II) 33C/19.

Note 4. Minas Gerais State Law 18.505, 4 November 2009, State of Minas Gerais, Brazil.

Note 5. Minas Gerais State Decree 45368, 5 May 2010, State of Minas Gerais, Brazil.

Note 6. UNESCO-IHE Institute for Water Education, November 2010. "Hidroex Capacity Strengthening Programme 2011-2014." Delft, the Netherlands.

Note 7. UNESCO-IHE Institute for Water Education, Hidroex Capacity building Activities 1 September 2012 10 April 2014. In early 2014, this contract was extended on a "no financial implications" basis through October 2014.

Note 8. The other UNESCO category I center is the International Center for Theoretical Physics in Trieste, Italy.

Note 9. Qualified applicants include those with a certified undergraduate degree in science or engineering, a minimum TOEFL (English) language score of 650 points (paper-based test) or 69 points (internet-based test), and a minimum of 3 years professional experience.

Note 10. Geo-processing, water and soil physical chemistry, hydrology and meteorology, biology, water effluents, 
microbiology, information technology, and distance education (video conferencing facility).

Note 11. CPLP Member Countries include: Portugal, Brazil, Mozambique, Angola, Guinea Bissau, Cape Verde, Sao Tomas and Principe, East Timor.

Note 12. In the NICHE program [Dutch Aid Program which is part of the Netherlands Organization for International Cooperation in Higher Education (NUFFIC)] the role is of Hidroex is to offer study tours for Mozambiqueans in Brazil. While Hidroex does not have course responsibilities in Mozambique under that award, some teaching role may emerge as the course development progresses.

Note 13. This includes support from the National Scientific and Technological Development Council (CNPq), Minas Gerais Research Support Foundation (FAPEMIG), and the Ministry of Science, Technology and Innovation (MCTI), and others.

\section{Copyrights}

Copyright for this article is retained by the author(s), with first publication rights granted to the journal.

This is an open-access article distributed under the terms and conditions of the Creative Commons Attribution license (http://creativecommons.org/licenses/by/3.0/). 